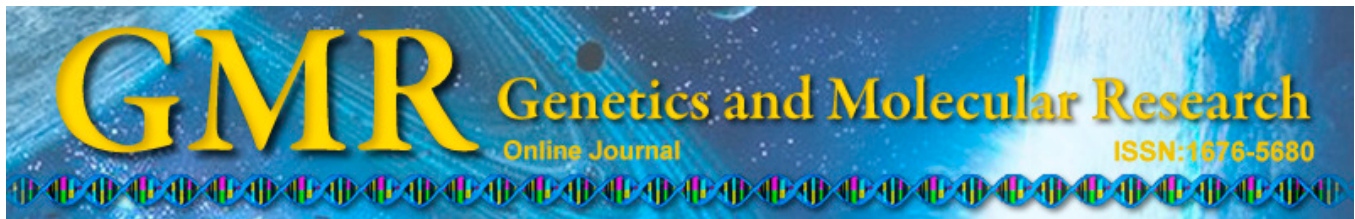

\title{
Molecular cloning and characterization of the full-length Hsp90 gene from Matricaria recutita
}

\author{
S.P. Ling, S.S. Su, H.M. Zhang, X.S. Zhang, X.Y. Liu, G.F. Pan and \\ Y. Yuan \\ College of Life Sciences, Anhui Agricultural University, Hefei China \\ Correspondence author: Y. Yuan \\ E-mail: zhiwuxue239@163.com
}

Genet. Mol. Res. 13 (4): 10994-11003 (2014)

Received June 10, 2014

Accepted September 23, 2014

Published December 19, 2014

DOI http://dx.doi.org/10.4238/2014.December.19.22

\begin{abstract}
Heat shock protein 90 (Hsp90) is one of the most abundant and conserved chaperone proteins and plays important roles in plant growth and responses to environmental stimuli. However, little is known regarding the sequence and function of Hsp90s in Matricaria recutita. In the present study, we cloned the full-length cDNA sequence of the $h s p 90$ gene from this species. Using rapid amplification of cDNA ends technologies with 2 degenerate primers that were designed based on the $h s p 90$ gene sequence from other members of Asteraceae, we isolated and characterized an Hsp90 homolog gene from M. recutita (Mr-Hsp90). The full-length Mr-hsp90 cDNA sequence, containing 2097 base pairs, encodes a protein of 698 amino acids. Based on amino acid sequence identity, Mr-Hsp90 showed high similarity to other cloned Hsp90 proteins. The Mr-Hsp90 protein was closely clustered with the Lactuca sativa in a phylogenetic tree. These results indicate that the cloned sequence of Mr-Hsp90 is a member of the Hsp90 family, which is reported for the first time in M. recutita. Next, we conducted a salt stress experiment to determine the protein's function under salt stress conditions. Survival of chamomile seedlings subjected to heat-shock pretreatment was significantly increased compared with groups that had not undergone heat-shock pretreatment in a salt stress
\end{abstract}


environment. This indicates that Mr-Hsp90 plays an important role in the salt resistance of chamomile seedlings.

Key words: Degenerate primers; Matricaria recutita; Mr-Hsp90; RACE; Salt resistance

\section{INTRODUCTION}

The heat shock protein 90 (Hsp90) family is one of the most conserved and abundant proteins in the cell and has been studied extensively in numerous organisms. A previous study showed that Hsp90 expression increased when plants were not only at high temperature, but also under abiotic stresses, such as drought, salinity, chemical toxicity, and oxidative stress. These abiotic stresses are serious threats to agriculture and cause deterioration of the environment (Wang et al., 2004). Hsp90 has been shown to refold proteins under abiotic stress (Vierling, 1991; Boston et al., 1996). The Hsp90 protein exists as a homodimer, and each monomer contains $1 \mathrm{~N}$-terminal ATP-binding domain, 1 middle domain, $1 \mathrm{C}$-terminal dimerization domain, and 3 flexible linked regions ( $\mathrm{Li}$ and Buchner, 2013). Hsp90 is mainly located in the cytoplasm, mitochondria, chloroplasts, and endoplasmic reticulum, but is rapidly transferred to the nucleus under stress conditions (Gupta, 1995; Hao et al., 2010). The Hsp90 family includes protein kinases, transcription factors, and steroid hormone receptors, and thus plays an essential role in metabolism, folding, translocation, and refolding of denatured proteins under both normal and stress conditions (Deshaies et al., 1988; Abernethy et al., 1989; Young et al., 2001). Because of its effects on hormone signaling, cell cycle control, differentiation and developmental processes (Pratt and Toft, 1997; Wegele et al., 2004; Shinozaki et al., 2006; Taipale et al, 2010; Zuehlke and Johnson, 2010), Hsp90 has become a target of cancer therapy (Kamal et al., 2003; Ali et al., 2006). In addition, a number of Hsp 90 proteins have been identified and characterized in plants (Yabe et al., 1994; Pareek et al., 1995; Milioni and Hatzopoulos, 1997; Liu et al., 2006), and these Hsp90 members share $63-71 \%$ amino acid similarity with those from yeast and animals.

Matricaria recutita (L.) Rauschert (Chamomile, Asteraceae) is one of the oldest and the most important medicinal plant species in Europe. The essential oil of the chamomile flower contains abundant chamazulene and bisabol and its oxides (alpha-alcohol oxide A and alpha-alcohol oxide B, for example) (Tubaro et al., 1984; McKay and Blumberg, 2006), which are the main anti-inflammatory agents (Schilcher et al., 2005). Chamomile also has significant anti-inflammatory (Shipochliev et al., 1981), anti-spasmodic (Maschi et al., 2008), bacteriostatic (Lis-Balchin et al., 1998), and antiviral (Aggag and Yousef, 1972; Koch et al., 2008) activities; therefore, it has been widely used in medicine, nutritio, and cosmetics. Chamomile originated in southeastern Europe and western Asia (Shiva et al., 2002); as a transplant species, it shows great potential in the Chinese market. Previous studies have shown that chamomile can grow in various types of soil, including alkaline land (Tucakov, 1957; Bhattacharjee, 2005). However, the mechanism of chamomile's resilience to natural conditions is not well-understood. Several reports have indicated that Hsp90 is closely related to the stress resistance of plants (Xu et al., 2013). Whether there is functional connection between Hsp90 and the stress resistance in $M$. recutita remains unknown. In this study, we first isolated the Hsp90 gene from M. recutita, known as Mr-hsp90, and examined its expression patterns in response to salt and thermal stress. Our results showed that the survival of $M$. recutita seedlings is related to the expression levels of Mr-Hsp90. 


\section{MATERIAL AND METHODS}

\section{Materials and reagents}

Chamomile flowers were obtained from the horticultural garden of Anhui Agricultural University and chamomile seedlings were cultured in illumination incubator. Plant materials were stored at $-80^{\circ} \mathrm{C}$.

The materials and reagents used in this study included an RNA extraction kit (RNAiso Plus), primerScript II first-strand cDNA Synthesis Kit, Agarose Gel DNA Extraction Kit, Taq DNA polymerase, LATaq, DL2000 DNA ladder Maker, and DL5000 DNA ladder Maker (Takara, Shiga, Japan), pEASY-T1 Simple Cloning Kit, Trans1-T1 Phage Resistant Chemically Competent Cells (TransGen Co., Ltd., Beijing, China), SMARTer ${ }^{\mathrm{TM}}$ RACE cDNA Amplification Kit (Clontech, Mountain View, CA, USA), PrimeScriptTM RT Master Mix, and SYBR Premix Ex Taq II. All primers and gene sequencing experiments were conducted by Shanghai ShengGong Biological Engineering Company (Shanghai, China).

\section{Obtaining partial fragments of the $h s p 90$ gene}

The total RNA of chamomile flowers was isolated using the RNAiso Plus (Takara) according to the manufacturer instructions. Transcribed cDNA was synthesized from total RNA using the PrimeScript II first-strand cDNA Synthesis Kit (Takara). To isolate fragments of terpene synthase genes, we designed degenerated oligonucleotides (Deg-Fwd and DegRev) based on conserved sequence elements of other Asteraceae Hsp90s found in GenBank (Table 1), and the PCR program was as follows: $94^{\circ} \mathrm{C}$ for $3 \mathrm{~min}, 35$ cycles of $94^{\circ} \mathrm{C}$ for $30 \mathrm{~s}$, $54^{\circ} \mathrm{C}$ for $30 \mathrm{~s}, 72^{\circ} \mathrm{C}$ for $1 \mathrm{~min}$, and a final extension at $72^{\circ} \mathrm{C}$ for $10 \mathrm{~min}$. The expected bands were purified and cloned into the pEASY-T1 vector (TransGen) and then 3 positive clones were sequenced. To confirm the cloned fragment, the sequence was compared with the Hsp90 sequence from Ageratina adenophora with BLASTx.

\begin{tabular}{ll}
\multicolumn{1}{c}{ Table 1. Primer sequences used in the experiment. } \\
\hline Primer names & Primer sequences $\left(5^{\prime}-3^{\prime}\right)$ \\
\hline Deg-Fwd & YTNGARYTNTAYGARGC \\
Deg-Rev & SWRAAYTGNGGYTCRAA \\
Gsp5 & GCATCGGCTCTCTTCCTTAGCTCCTCCA \\
Gsp3 & TGGGCGACAAGGTCGAAAAGGTTGTTGT \\
QRTfwd & CCTTTTGTTCCCAAGCGGG \\
QRTrev & TCGGGGATAAGCTCCTCACA \\
18SQfwd & ATGA TAACTCGACGGATCGC \\
18SQrev & CTTGGATGTGGTAGCCGTTT \\
actQfwd & GCTAACAGGGAAAAGATGACTC \\
\hline
\end{tabular}

\section{Rapid amplification of cDNA ends (RACE)}

RACE-ready cDNA was prepared using the SMARTer RACE cDNA Amplification Kit according to the manufacturer instructions (Clontech). The gene-specific primers, Gsp5 and Gsp3, were designed according to fragments of Hsp90 to extend its 5' and 3' ends (Table 1). The 
PCR was as follows: $94^{\circ} \mathrm{C}$ for $3 \mathrm{~min}, 35$ cycles of $94^{\circ} \mathrm{C}$ for $30 \mathrm{~s}, 65^{\circ} \mathrm{C}$ for $30 \mathrm{~s}$, and $72^{\circ} \mathrm{C}$ for 1 min, with extension at $72^{\circ} \mathrm{C}$ for $10 \mathrm{~min}$. Subsequent steps were as described above.

\section{Bioinformatic analysis}

Searches for nucleotide and amino acid sequence similarities were conducted using the blast programs at the NCBI website (http://blast.ncbi.nlm.nih.gov/Blast.cgi). The open reading frame was identified by the open reading frame finder (http://www.ncbi.nlm.nih.gov/ projects/gorf/). A phylogenetic tree was constructed based on the similarity of Hsp90 amino acids between $M$. recutita and other species using Crustal X. Multiple sequence alignment was performed using Clustal W (http://www.ch.embnet.org/software/ClustalW.html).

\section{Salt stress test}

We cultured chamomile seedlings (16 days after sow) in sand containing $0-200 \mathrm{mM}$ $\mathrm{NaCl}$. Some of the chamomile seedlings were first treated by heat-shock for $20 \mathrm{~min}$ at $42^{\circ} \mathrm{C}$, recovered for $4 \mathrm{~h}$ at $25^{\circ} \mathrm{C}$, and then cultured in sand containing $200 \mathrm{mM} \mathrm{NaCl}$ for the salt stress test; untreated seedlings were used as the control group (all groups were cultured at $25^{\circ} \mathrm{C}$ under full sunlight). The survival rate of seedlings was calculated after 2 days of treatment. Total RNA of these seedlings was extracted to determine the transcriptional expression of Hsp90 with quantitative real-time PCR (qRT-PCR). qRT-PCR was performed for each cDNA template using the SYBR Green Supermix in an Applied Biosystems 7300 real-time PCR system (Foster City, CA, USA). Reaction specificity was verified by melting curve analysis. The relative mRNA level for each gene was calculated as a $2^{-\Delta \Delta C t}$ value (Livak and Schmittgen, 2001).

\section{RESULTS}

\section{Cloning and sequence analysis of Mr-Hsp90}

The BLASTx analysis showed that the open reading frame sequenced obtained had high similarity with Hsp90 from lettuce (96\%). The full-length open reading frame of MrHsp90 contains 2097 base pairs, from which a protein of 698 amino acids is produced (approximately $80 \mathrm{kDa}$ ). A 92-base pair sequence of the $5^{\prime}$ untranslated region and 176-base pair sequence of the 3' untranslated region were also cloned. The full-length cDNA sequence was assigned to GenBank under the accession number of KF589869. Using the Interpro database (http://www.ebi.ac.uk/interpro/), we analyzed the amino acid sequence of the Mr-Hsp90 protein. The results also confirmed that Mr-Hsp90 is a member of the Hsp90 family. The $\mathrm{Mr}-\mathrm{Hsp} 90$ sequence includes a highly-conserved N-terminal domain, a conserved acidic Cterminal domain, 3 flexible linker regions, and ribosomal protein S5 domain 2-like.

We aligned Mr-Hsp90 and its homologs from other species identified in the NCBI database (Figure 1). Pairwise comparison analysis indicated that the highest identity was with Lactuca sativa at $94.48 \%$, while the identity with other species such as Homo sapiens was $57.71 \%$, Heterodera glycines was $62.46 \%$, Mythimna separata was $56.60 \%$, Mus musculus was $65.50 \%$, and Salmo salar was $55.32 \%$. All of these Hsp90 proteins share the conserved amino acid sequence G (V/I) VDS EDLPLNISRE, which is a signature of the Hsp90 protein family (Figure 1, underlined black-box). The consensus sequence MEEV(D/E) (Figure 1, un- 
derlined red-box) at the C-terminus was also identified in the Mr-Hsp90 sequence. The $\mathrm{Mr}-$ Hsp90 protein was closely clustered with the Lactuca sativa in a phylogenetic tree (Figure 2).

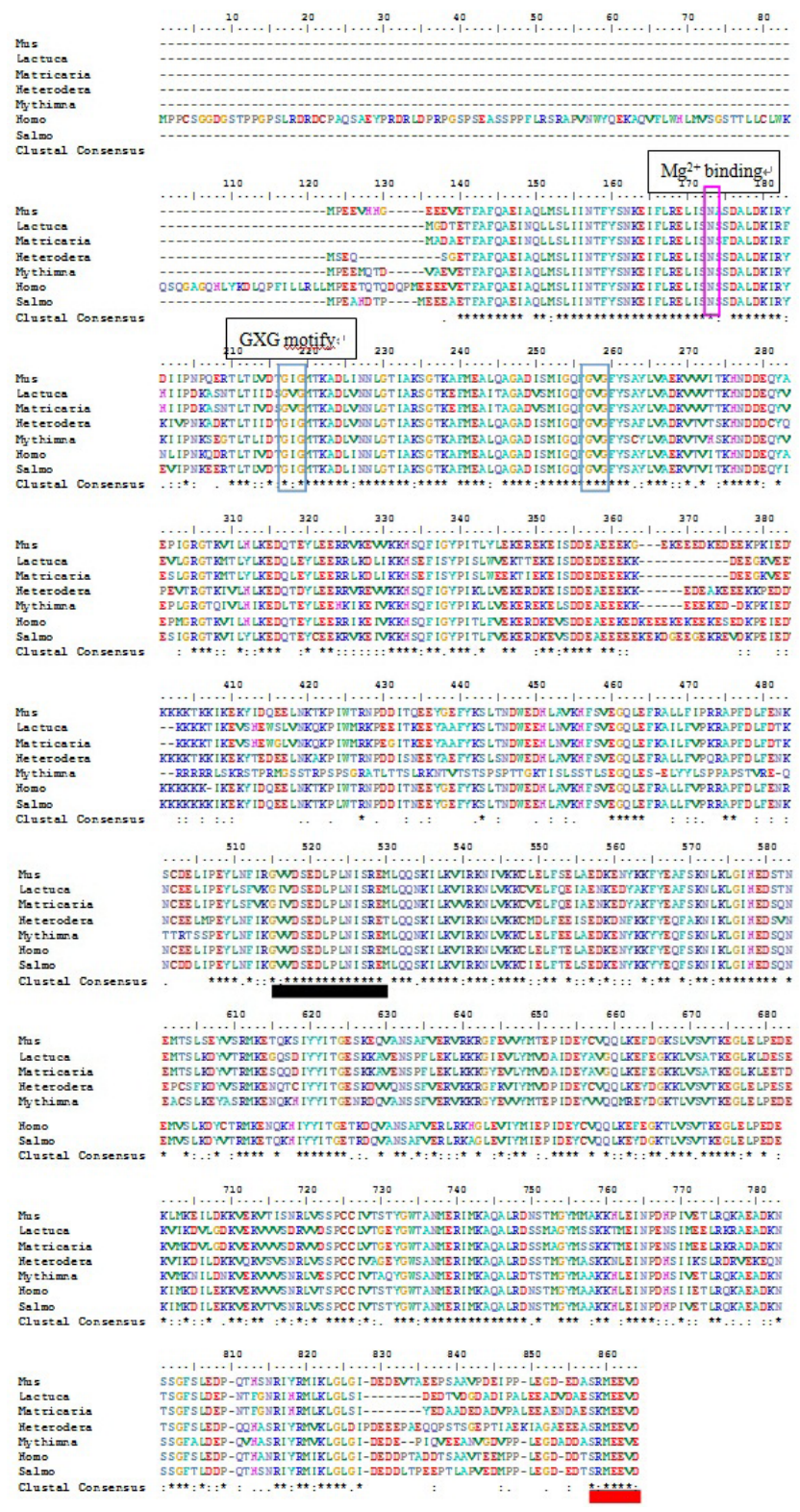

Figure 1. Alignment of Matricaria recutita Hsp90 with its homologs identified in the NCBI database. The species included Lactuca sativa (AFQ94045.1), Heterodera glycines (ACR57216.1), Mythimna separata (ABY55234.1), Homo sapiens (NP_001017963.2), Mus musculus (NP_032328.2), and Salmo salar (NP_001167173.1). Identical amino acids are boxed, and the asterisks, double dots, and single dots denote fully conserved amino acid residues, strongly conserved amino acid residues, and weakly conserved amino acid residues, respectively. $\mathrm{Mg}^{2+}$ binding sites and GXG locus are shown with pink and blue boxes. 


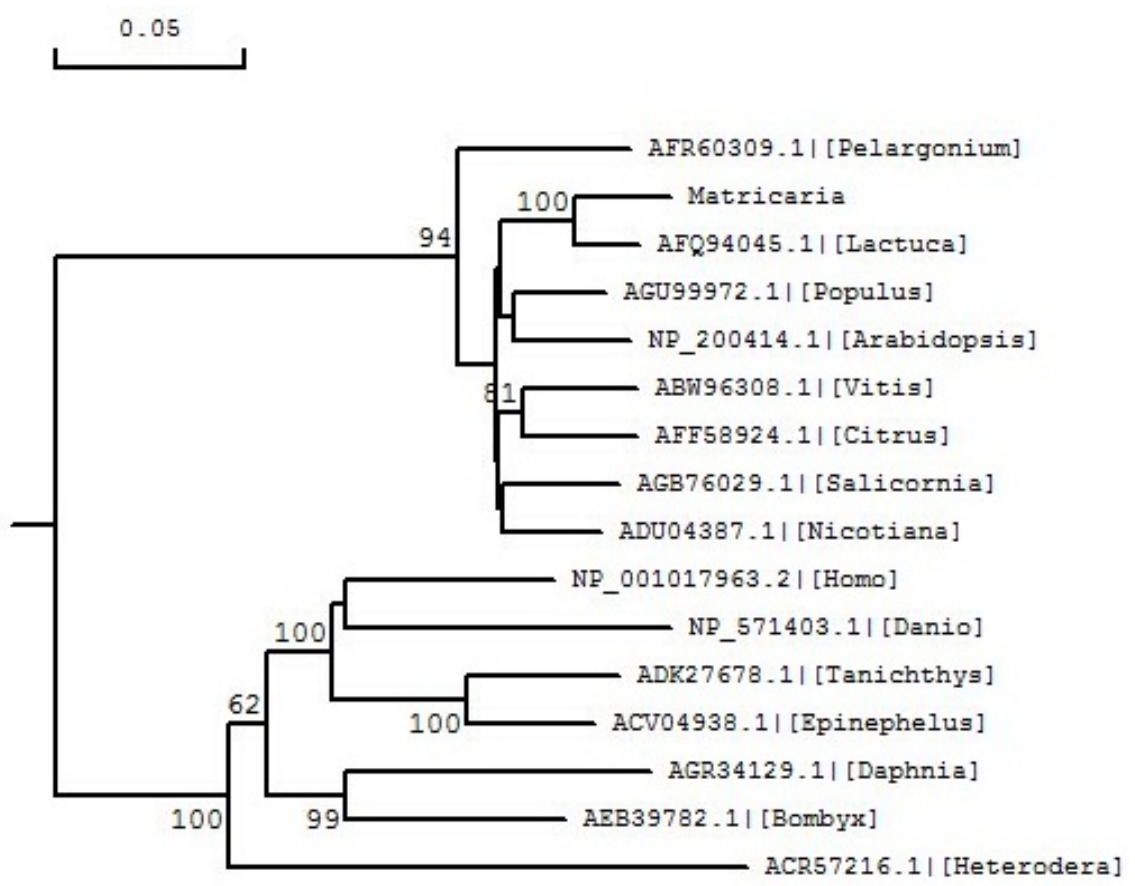

Figure 2. Phylogenetic analysis of Hsp90 sequences. Phylogenetic tree was generated using Hop amino acids of 16 species from insects, fish, plants, and mammals. The percentage of bootstrap values obtained from 1000 re-samplings are shown at the nodes and the value lower than 60 was deleted. Sequences used for analysis included: AGB76029.1 (Salicornia europaea), AFQ94045.1 (Lactuca sativa), ADU04387.1 (Nicotiana attenuata), ABW96308.1 (Vitis pseudoreticulata), AFF58924.1 (Citrus sinensis), AFR60309.1 (Pelargonium peltatum), AGU99972.1 (Populus tomentosa), NP_001017963.2 (Homo sapiens), ACR57216.1 (Heterodera glycines), NP_571403.1 (Danio rerio), ADK27678.1 (Tanichthys albonubes), ACV04938.1 (Epinephelus coioides), NP_200414.1 (Arabidopsis thaliana), AGR34129.1 (Daphnia pulex), and AEB39782.1 (Bombyx mori).

\section{Seedling survival rate and transcriptional level of Mr-Hsp90 under salt and heat stresses}

Using qRT-PCR, we detected the expression of Mr-Hsp90 under normal conditions and salt and thermal stress conditions. Expression of Mr-hsp90 in untreated chamomile seedlings changed little when grown in sandy soil containing $0 \mathrm{mM} \mathrm{NaCl}$. With increasing $\mathrm{NaCl}$ concentration, the survival of chamomile seedlings decreased (Figure 3). When the cultured chamomile seedlings were pretreated at $42^{\circ} \mathrm{C}$ for $20 \mathrm{~min}$ in sandy soil containing $200 \mathrm{mM}$ $\mathrm{NaCl}$, we found that the survival rate of seedlings $(73.68 \%)$ increased significantly compared with those directly treated with salt (47.62\%). Using qRT-PCR, the transcriptional level of Hsp90 in heat-pretreated seedlings was approximately 4-fold higher compared to the control groups (Figure 4).

\section{DISCUSSION}

Hsp90s are thought to play an important role in stress responses during plant develop- 


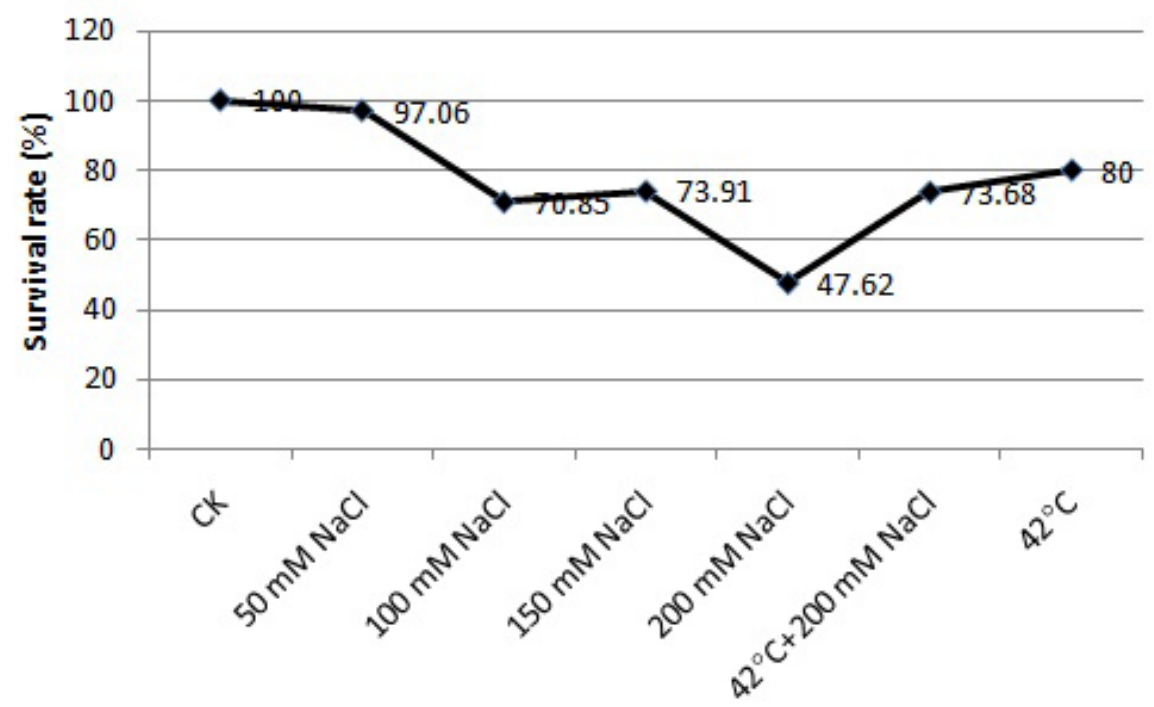

Figure 3. Survival rate of chamomile seedlings under different stresses. Five chamomile seedling groups were grown in sandy soil containing $0,50,100,150$, or $200 \mathrm{mM} \mathrm{NaCl}$, another 2 groups included the chamomile seedling group (16 days) pretreated at $42^{\circ} \mathrm{C}$ for 20 min grown in sandy soil containing $200 \mathrm{mM} \mathrm{NaCl}$ and the chamomile seedling group (16 days) pretreated at $42^{\circ} \mathrm{C}$ for 20 min grown in sandy soil without $\mathrm{NaCl}$.

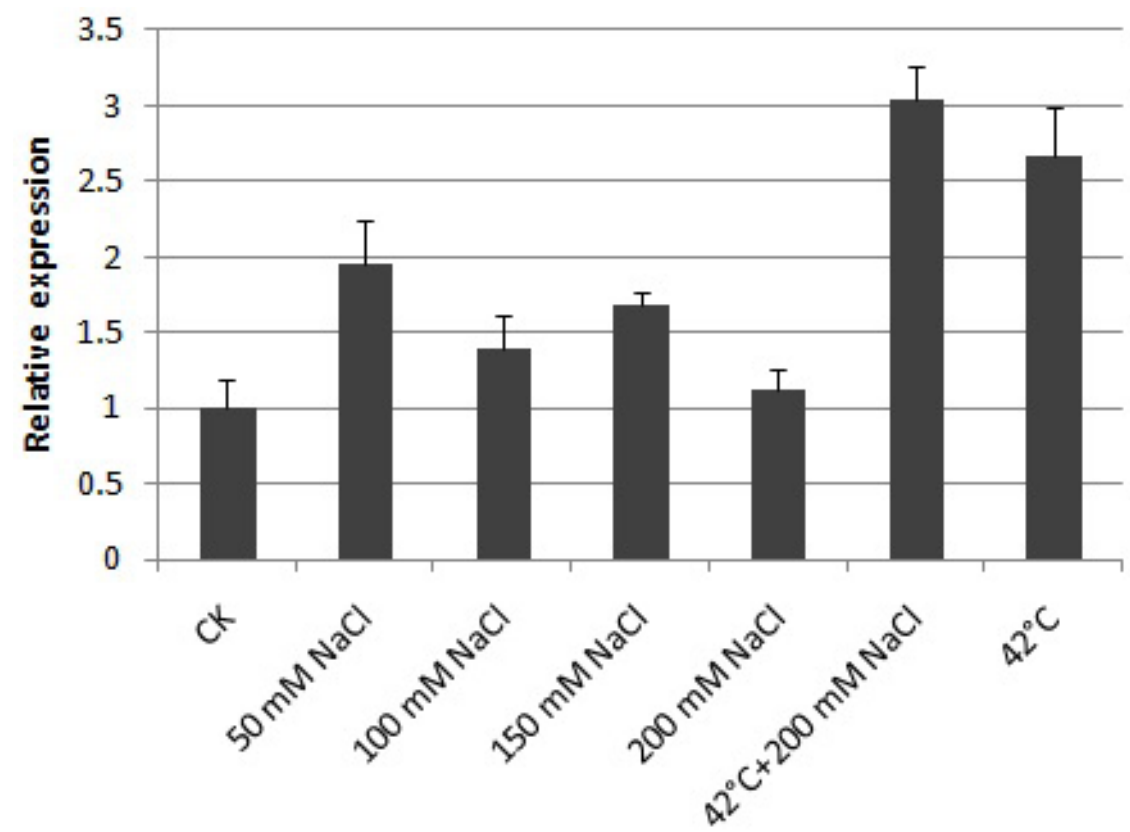

Figure 4. qRT-PCR analyses of the relative expression of chamomile seedlings' Mr-Hsp90 under different stresses. Five groups of chamomile seedlings were grown in sandy soil containing $0,50,100,150$, and $200 \mathrm{mM} \mathrm{NaCl}$. Additional 2 groups included the chamomile seedling group ( 16 days) pretreated at $42^{\circ} \mathrm{C}$ for 20 min grown in sandy soil containing $200 \mathrm{mM} \mathrm{NaCl}$ and the chamomile seedling group (16 days) pretreated at $42^{\circ} \mathrm{C}$ for 20 min grown in sandy soil without $\mathrm{NaCl}$. 
ment (Xu et al., 2012). Cloning of full-length Mr-Hsp90 cDNA is the first step for structural and functional studies of this protein in $M$. recutita and examining the molecular mechanisms of Mr-Hsp90 in the cellular stress response. In this study, the full-length cDNA of Mr-hsp90 was cloned and reported for the first time in $M$. recutita, which can provide a molecular basis for future studies of the role of Hsp90 in chamomile.

Bioinformatic analysis revealed that $\mathrm{Mr}-\mathrm{Hsp} 90$ contains a conserved N-terminal domain, which is the ATP/ADP binding site with intrinsic ATPase activity. Binding and hydrolysis of ATP can cause conformational transitions of Hsp90 between an open conformation with the $\mathrm{N}$-domains separated and a closed conformation with the N-domains associated (Hessling et al., 2009; Mickler et al., 2009). A conserved MEEVD motif at the end of C-terminus serves as a docking site for the interaction with co-chaperones that contains a tetratricopeptide repeat clamp (Jackson et al., 2004). Phylogenetic analysis also confirmed that Mr-Hsp90 is most closely related to L. sativa. Thermal resistance experiments showed that seedling survival and the transcriptional level of Hsp90 in the heat-pretreated group were clearly increased. These results suggest that the survival rate of seedlings is closely correlated with Mr-Hsp90 expression.

The Mr-Hsp90 gene we cloned is a member of the Hsp90 family, which may improve the salt and thermal resistance of the $M$. recutita. Additionally, Mr-Hsp90 plays an important role in the survival of chamomile seedlings under salty and thermal resistance conditions. Thus, similarly to other member of the Hsp90 family, Mr-Hsp90 is closely related to the survival rate of Matricaria seedlings and is important in the responses to salty and thermal resistance of Matricaria.

\section{CONCLUSIONS}

In summary, we cloned the Hsp90 gene from M. recutita and investigated its expression under salty and thermal stress conditions. The survival rate of seedlings decreased with increasing salt concentration. The mRNA of Mr-Hsp90 expression under salt stress did not increase. Our study indicates that Mr-Hsp90 is a member of the Hsp90 family and that the expression of Mr-Hsp90 is correlated with stress resistance in M. recutita.

\section{ACKNOWLEDGMENTS}

We would like to thank Associate Prof. Dahui Li for improving the language of the manuscript (Anhui Agricultural University, China) and Jijun Chen for improving the writing (Nanjing University, China). Research supported by the Hefei Technology Bureau.

\section{REFERENCES}

Abernethy RH, Thiel DS, Petersen NS and Helm K (1989). Thermotolerance is developmentally dependent in germinating wheat seed. Plant Physiol. 89: 569-576.

Aggag ME and Yousef RT (1972). Study of antimicrobial activity of chamomile oil. Planta Med. 22: 140-144.

Ali MM, Roe SM, Vaughan CK, Meyer P, et al. (2006). Crystal structure of an Hsp90-nucleotide-p23/Sba1 closed chaperone complex. Nature 440: 1013-1017.

Bhattacharjee SK (2005). Handbook of Aromatic Plants. Pointer Publishers, Jaipur, India, 277-279.

Boston RS, Viitanen PV and Vierling E (1996). Molecular chaperones and protein folding in plants. Plant Mol. Biol. 32: 191-222.

Deshaies RJ, Koch BD, Werner-Washburne M, Craig EA, et al. (1988). A subfamily of stress proteins facilitates 
translocation of secretory and mitochondrial precursor polypeptides. Nature 332: 800-805.

Gupta RS (1995). Phylogenetic analysis of the 90kD heat shock family of protein sequences and an examination of the relationship among animals, plants, and fungi species. Mol. Biol. Evol. 12: 1063-1073.

Hao H, Naomoto Y, Bao X, Watanabe N, et al. (2010). HSP90 and its inhibitors. Oncol. Rep. 23: 1483-1492.

Hessling M, Richter K and Buchener J (2009). Dissection of the ATP-induced conformational cycle of the molecular chaperone Hsp90. Nat. Struct. Mol. Biol. 16: 287-293.

Jackson SE, Queistch C and Toft D (2004). Hsp90: From structure to phenotype. Nat. Struct. Mol. Biol. 11: 1152-1155.

Kamal A, Thao L, Sensintaffar J, Zhang L, et al. (2003). A high-affinity conformation of Hsp90 confers tumour selectivity on Hsp90 inhibitors. Nature 425: 407-410.

Koch C, Reichling J, Schneele J and Schnitzler P (2008). Inhibitory effect of essential oils against herpes simplex virus type 2. Phytomedicine 15: 71-78.

Li J and Buchner J (2013). Structure, function and regulation of the Hsp90 machinery. Biomed J. 36: 106-117.

Lis-Balchin M, Deans SG and Eaglesham E (1998). Relationship between bioactivity and chemical composition of commercial essential oil. Flavour Frag. J. 13: 98-104.

Liu D, Zhang X, Cheng Y, Takano T, et al. (2006). rHsp90 gene expression in response to several environmental stresses in rice (Oryza sativa L). Plant Physiol. Biochem. 44: 380-386.

Livak KJ and Schmittgen TD (2001). Analysis of relative gene expression data using real-time quantitative PCR and the 2(-Delta Delta C(T)) method. Methods 25: 402-408.

Maschi O, Cero ED, Galli GV, Caruso D, et al. (2008). Inhibition of human cAMP- phosphodiesterase as a mechanism of the spasmolytic effect of Matricaria recutita L. J. Agric. Food Chem. 56: 5015-5020.

McKay DL and Blumberg JB (2006). A review of the bioactivity and potential health benefits of chamomile tea (Matricaria recutita L.). Phytother. Res. 20: 519-530.

Mickler M, Hessling M, Ratzke C, Buchner J, et al. (2009). The large conformational changes of Hsp90 are only weakly coupled to ATP hydrolysis. Nat. Struct. Mol. Biol. 16: 281-286.

Milioni D and Hatzopoulos P (1997). Genomic organization of hsp90 gene family in Arabidopsis. Plant Mol Biol. 35: 955-961.

Pareek A, Singla SL and Grover A (1995). Immunological evidence for accumulation of two high-molecular-weight (104 and $90 \mathrm{kDa}$ ) HSPs in response to different stresses in rice and in response to high temperature stress in diverse plant genera. Plant Mol. Biol. 29: 293-301.

Pratt WB and Toft DO (1997). Steroid receptor interactions with heat shock protein and immunophilin chaperones. Endocr. Rev. 18: 306-360.

Schilcher H, Imming P and Goeters S (2005). Active Chemical Constituents of Matricaria chamomilla L. syn. Chamomilla recutita (L.) Rauschert. In: Chamomile: Industrial Profiles (Franke R and Schilcher H, eds.). CRC Press, Boca Raton, 56-76.

Shinozaki F, Minami M, Chiba T, Suzuki M, et al. (2006). Depletion of Hsp90ß induces multiple defects in B cell receptor signaling. J. Biol. Chem. 281: 16361-16369.

Shipochliev T, Dimitrov A and Aleksandrova E (1981). Anti-inflammatory action of a group of plant extracts. Vet. Med. Nauki. 18: 87-94.

Shiva MP, Lehri A and Shiva A (2002). Aromatic and Medicinal Plants Yielding Essential Oil for Pharmaceutical, Perfumery, Cosmetic Industries and the Trade. 1st edn. International Book Distributors, India, pp. 223-228.

Taipale M, Jarosz DF and Lindquist S (2010). Hsp90 at the hub of protein homeostasis: emerging mechanistic insights. Nat. Rev. Mol. Cell Biol. 11: 515-528.

Tubaro A, Zilli C, Redaelli C and Loggia RD (1984). Evaluation of antiinflammatory activity of a chamomile extract after topical application. Planta Med. 50: 359.

Tucakov J (1957). The areas and the exploitation of the Matricaria chamomilla L. in Jugoslavia. Plant Foods Hum. Nutr. 2: $161-173$.

Vierling E (1991). The roles of heat shock proteins in plants. Annu. Rev. Plant Physiol. Plant Mol. Biol. 42: 579-620.

Wang W, Vinocur B, Shoseyov O and Altman A (2004). Role of plant heat-shock proteins and molecular chaperones in the abiotic stress response. Trends Plant Sci. 9: 244-252.

Wegele H, Muller L and Buchner J (2004). Hsp70 and Hsp90-a relay team for protein folding. Rev. Physiol. Biochem. Pharmacol. 151: 1-44.

Xu J, Xue C, Xue D, Zhao J, et al. (2013). Overexpression of GmHsp90s, a heat shock protein 90 (Hsp90) gene family cloning from soybean, decrease damage of abiotic stresses in Arabidopsis thaliana. PLoS One 8: e69810.

Xu ZS, Li ZY, Chen Y, Chen M, et al. (2012). Heat shock protein 90 in plants: molecular mechanisms and roles in stress responses. Int. J. Mol. Sci. 13: 15706-15723. 
Yabe N, Takahshi T and Komeda Y (1994). Analysis of tissue-specific expression of Arabidopsis thaliana HSP90-family gene HSP81. Plant Cell Physiol. 35: 1207-1219.

Young JC, Moarefi I and Hartl FU (2001). Hsp90: a specialized but essential protein-folding tool. J Cell Biol. 154: 267-273.

Zuehlke A and Johnson JL (2010). Hsp90 and co-chaperones twist the functions of diverse client proteins. Biopolymers 93: 211-217. 